\title{
Prevalence of undiagnosed mild cognitive impairment in elderly patients undergoing thoracic surgery and its relationship with postoperative outcome: a prospective cohort study
}

\section{chaoyang tong}

Shanghai Jiao Tong University Affiliated Chest Hospital

dehua wu

Shanghai Jiao Tong University Affiliated Chest Hospital

yaofeng shen

Shanghai Jiao Tong University Affiliated Chest Hospital

meiyingXu ( $\nabla$ xmyxk123@163.com)

Shanghai Jiao Tong University Affiliated Chest Hospital https://orcid.org/0000-0002-5836-6238

\section{Research article}

Keywords: Mild cognitive impairment, Elderly patients, Thoracic surgery, Postoperative pulmonary complications.

Posted Date: July 12th, 2019

DOI: https://doi.org/10.21203/rs.2.11321/v1

License: (c) (i) This work is licensed under a Creative Commons Attribution 4.0 International License.

Read Full License 


\section{Abstract}

Background The prevalence of undiagnosed mild cognitive impairment $(\mathrm{MCl})$ in elderly patients scheduled for thoracic surgery and its association with adverse clinical outcomes is still unproven. Methods We enrolled 170 patients 65 year of age or older who were scheduled for thoracic surgery. 82 males and 88 females with ASA grade II-III. All the elderly patients were tested with Chinese modified version of MoCA preoperatively. According to the test results, they were divided into two groups: group $\mathrm{N}$ (MoCA score>25) and group AN (MoCA score $\leq 25)$. Outcomes included the hospital length of stay (primary outcome), the length of stay in patients with PPCs (LOS-PPCs), the pulmonary complications (atelectasis, pulmonary infection, respiratory failure) and other complications (blood transfusion, chylothorax, new arrhythmia, myocardial infarction and acute cerebral infarction) (secondary outcomes). Data were analyzed using univariate and multivariate analyses. Results Seventy-four of $154(49 \%)$ patients screened positive for probable mild cognitive impairment (MoCA $\leq 25)$ in the final analyses. The hospital length of stay and LOS-PPCs in elderly patients with mild cognitive impairment preoperatively were significantly longer than those with group $N(P<0.05)$. Multivariate stepwise regression showed that preoperative $\mathrm{MCl}$ was an independent risk factor for prolonging the hospital length of stay and LOS-PPCs. Patients with a MoCA score less than or equal to 25 were more likely to have a longer hospital length of stay $(\mathrm{OR}=2.355,95 \% \mathrm{Cl}=1.137$ to $4.877, \mathrm{P}=0.021)$ and $\mathrm{LOS}-\mathrm{PPCs}(\mathrm{OR}=6.867,95 \% \mathrm{Cl}=1.116$ to 42.257 , $\mathrm{P}=0.038)$, but not related to increase the incidence of postoperative pulmonary complications $(\mathrm{OR}=$ $0.955,95 \% \mathrm{Cl}=0.280$ to $3.254, \mathrm{P}=0.941)$ and other complications $(\mathrm{OR}=1.687,95 \% \mathrm{Cl}=0.502$ to 5.665 , $\mathrm{P}=0.398)$ compared to those with a MoCA score greater than 25. Conclusions The prevalence of undiagnosed probably mild cognitive impairment among elderly patients scheduled for thoracic surgery is high (49\%). Such impairment is associated with a longer hospital stay and LOS-PPCs, while it is not possible to conclude that it is related to the incidence of pulmonary complications and other complications after surgery.

\section{Background}

Preoperative assessment of vital organ function is a routine work ${ }^{[1-3]}$, while brain function assessment is not carried out routinely due to limited clinical testing methods ${ }^{[4]}$. Previous epidemiological surveys showed the prevalence of cognitive impairment in the elderly population is quite high, ranged from $35 \%$ to $50 \%$ in the population aged $\geq 65$ years have different degrees of cognitive impairment ${ }^{[5-6]}$. Preoperative cognitive impairment could lead to delicate and persistent cognitive impairment in elderly patients after surgery ${ }^{[7-9]}$. Annie et al ${ }^{[10]}$ have shown that mild cognitive impairment $(\mathrm{MCl})$ is associated with an increased risk of postoperative delirium and severity. Alex et al ${ }^{[11]}$ study also showed that $\mathrm{MCl}$ increases the risk of postoperative cognitive dysfunction (POCD) in elderly patients. Postoperative neurocognitive dysfunction (PND) could prolong hospital stay, increase medical expenses, decrease quality of life, and increase morbidity and mortality of elderly patients ${ }^{[5,12-13]}$. Impaired cognitive function is a risk factor for perioperative adverse outcome in elderly patients. Focusing on preoperative cognitive function in elderly patients is a significant topic. The American College of Surgeons and the American Geriatrics Society 
have recently published a joint guideline recommending preoperative cognitive function assessment in

elderly patients ${ }^{[14]}$. However, the relationship between $\mathrm{MCl}$ screening and postoperative adverse clinical outcomes in elderly patients undergoing thoracic surgery is still unclear. The Montreal Cognitive Assessment (MoCA) is mainly used to screen $\mathrm{MCl}$ in elderly patients. This study hypothesized that preoperative $\mathrm{MCl}$ based on the MoCA scale could predict patients' adverse clinical outcomes and provide a reference for clinical practice.

\section{Methods}

\section{Study design and patient population}

This prospective cohort study enrolled 170 patients from Nov, 7, 2018 to April, 1, 2019. This study was approved by the Institutional Review Board (KS1862) of Shanghai Jiao tong University Shanghai Chest Hospital with the consent of the patient or family member and signed informed consent (Chinese Clinical Trial Registry number, ChiCTR1800019526).

\section{Criteria for inclusion and exclusion}

Elderly patients of ASA I-III grade, aged 65 years and over, who were scheduled to undergo thoracic surgery were selected. Exclusion criteria: (1)Mental disorders such as anxiety, depression, dementia, etc., which have been clearly diagnosed by patients; (2)Uncorrected visual or hearing impairment (unable to see pictures or read or understand instructions);(3) Inability to understand the researchers' speech; (4)Combined with severe cardiovascular and cerebrovascular diseases;(5)Liver and kidney dysfunction, etc., (6)Have been included in other studies.

\section{Preoperative preparations and anesthesia protocol}

Elderly patients enrolled in this study were assessed by a trained investigator in a quiet anesthesia preparation room on a Chinese modified version of the MoCA scale. According to the results of MoCA Scale (MoCA Test includes memory, attention, orientation, visual space and executive ability, speech ability and other cognitive domain tests, the total score is 30 , the length of education is 6-12 years, the total score is +1 , the length of education is less than 6 years, the total score is +2 , the score is less than 25 points as the existence of $\mathrm{MCl}$ ), the patients were divided into $\mathrm{N}$ group (MoCA score $>25$ ) and AN group (MoCA score $\leq 25)^{[15]}$.

Patients were monitored with electrocardiography, non-invasive blood pressure, pulse oximetry, capnography and bispectral index. General Anesthesia was induced with $0.6 \mu \mathrm{g} / \mathrm{kg}$ sufentanil and a target-controlled infusion of propofol set to a plasma concentration of $4 \mu \mathrm{g} / \mathrm{ml}$, cisatracurium $0.2 \mathrm{mg} / \mathrm{kg}$ 
was given to facilitate double-lumen bronchial tube intubation. Propofol administration was adjusted to of $2.5 \mu \mathrm{g} / \mathrm{ml}$ and Cisatracurium adjusted to $0.12 \mathrm{mg} / \mathrm{kg} / \mathrm{hour}$, remifentanil adjusted to $0.1 \mathrm{ug} / \mathrm{kg} / \mathrm{h}$ in the maintenance period. Invasive blood pressure monitoring was achieved by radial artery cannulation (IBP) and right internal jugular central venous catheterization (CVP). Patients were placed in lateral decubitus. Sufentanil5 $\mu$ g was given before skin incision. PCA pump was used in all patients after operation. The drug used in the pump was sufentanil $1 \mathrm{ug} / \mathrm{kg}+$ dezocine $0.4 \mathrm{mg} / \mathrm{kg}$ (diluted to $100 \mathrm{ml}$ saline, continuous dose $2 \mathrm{ml} / \mathrm{h}$, PCA $0.5 \mathrm{ml}$, locking time 15 minutes).

\section{Measurements}

The demographic data of patients and baseline data, including gender, age, ASA grade, BMI, history of hypertension, diabetes, cerebral infarction, radiotherapy and chemotherapy were recorded. The operation time, surgical procedure (VATS/thoracotomy/robotic assisted VATS), type of operation (anatomical lobectomy-segment, lobectomy/non-anatomical lobectomy-wedge resection), type of anesthesia (general anesthesia-GA/general anesthesia combined paravertebral-GA-PA), intraoperative accident (hypoxemia -

refers to $\mathrm{SpO}_{2}<92 \%$, lasting for more than 10 minutes), total fluid volume and the duration from PACU to extubation were also recorded. The primary outcome was the hospital length of stay. Secondary outcomes were the length of stay in patients with PPCs (LOS-PPCs), the pulmonary complications (atelectasis, pulmonary infection, respiratory failure) and other complications (blood transfusion, chylothorax, new arrhythmia, myocardial infarction and acute cerebral infarction). Prolonged hospital stay refers to postoperative hospital stay for more than or equal to 5 days. Postoperative pulmonary complications (PPCs) were defined according to the European Perioperative Clinical Outcome (EPCO) definition.

\section{Statistical analysis}

SPSS22.0 statistical software (SPSS Inc. Chicago, IL, USA) was used for data processing. The measurement data were expressed as mean \pm standard deviation (SD) or median (interquartile range). Frequency and percentage were used for counting data. Two independent sample t-test was used to compare the continuous variables with normal distribution. Mann-Whitney U-test was used to compare the continuous variables with non-normal distribution. Chi-square test or Fisher exact test were used to compare the counting data. We used Kaplan-Meier estimates for length of stay and LOS-PPCs.

Univariate and multivariate analysis of $\mathrm{MCl}$ screening predict the risk of length of stay, LOS-PPCs, the incidence of PPCs and other complications after surgery. Covariate $p$-value $<0.1$ in univariate analysis was included in multivariate analysis. A $p$-value $<0.05$ was statistically significant.

Based on previous clinical studies ${ }^{[16-17]}$, preoperative $\mathrm{MCl}$ increases the hospital length of stay, but whether it increases the incidence of postoperative complications remains unclear. Therefore, the sample size of this study may be more reasonable based on the hospital length of stay. Sample size calculation 
based on the reference literature ${ }^{[5-6]}$ and pre-test results showed that the incidence of $\mathrm{MCl}$ in elderly patients was about $40 \%$, the length of stay after thoracic surgery was about $4 \pm 2$ days, and the average length of stay in elderly patients with $\mathrm{MCl}$ was increased by 1 day, according to $=0.05,=0.2$. It was estimated that $10 \%$ of the missing rate would eventually need to be included in 146 patients.

\section{Results}

A total of 170 patients were enrolled in this study, however, fourteen patients were excluded, two patients for lack of follow-up, and 154 patients were included in the final analyses (Figure1).

There were no significant differences in pre-and intraoperative patient characteristics between the two groups (Table 1).

The hospital length of stay and LOS-PPCs in AN (MoCA score $\leq 25)$ group were significantly longer than those in $\mathrm{N}$ (MoCA score>25) group (Figure2-3).

Univariate and multivariate analysis of $\mathrm{MCl}$ screening results predict the risk of length of stay and LOSPPCs. Multivariate stepwise regression analysis showed that patients with a MoCA score less than or equal to 25 were more likely to have a longer hospital length of stay $(\mathrm{OR}=2.355,95 \% \mathrm{Cl}=1.137$ to 4.877 , $P=0.021)$ and LOS-PPCs $(\mathrm{OR}=6.867,95 \% \mathrm{Cl}=1.116$ to $42.257, P=0.038)$. The variables of $P<0.1$ in univariate analysis and multivariate stepwise regression analysis are shown in Table 2-3.

Univariate and multivariate analysis of $\mathrm{MCl}$ screening results predict the risk of the incidence of PPCs and other complications. Multivariate regression analyses showed that patients with a MoCA score less than or equal to 25 were not related to increase the incidence of PPCs (OR $=0.955,95 \% \mathrm{Cl}=0.280$ to 3.254 , $P=0.941)$ and other complications $(\mathrm{OR}=1.687,95 \% \mathrm{Cl}=0.502$ to $5.665, P=0.398)$ compared to those with a MoCA score greater than 25 .

\section{Discussion}

These data confirm that poor preoperative cognition as assessed by MoCA screening is both prevalent among geriatric patients scheduled for thoracic surgery and predictive of adverse clinical outcomes including a longer hospital stay and LOS-PPCs. In contrast, $\mathrm{MCl}$ preoperatively were not associated with the incidence of postoperative pulmonary complications and other complications. Preoperative cognitive risk screening may help identify those at greatest risk for adverse clinical outcomes, so interventions designed to potentially guide and enhance the care can be targeted to those most likely to benefit.

The Chinese modified MoCA Scale adopted in this study is mainly used to evaluate $\mathrm{MCl}$ in elderly patients, including visual space and executive function, naming, abstraction, memory, attention and orientation. It has high acceptance and credibility ${ }^{[18-19]}$. The best cut-off point is 25 points, and it has high sensitivity (90\%) and specificity $(87 \%){ }^{[20]}$. We used the MoCA scale of the approximate "gold standard" for $\mathrm{MCl}$ assessment, and realized that some people who were assessed as $\mathrm{MCl}$ before surgery 
may be normal. That about one in two geriatric patients scheduled for thoracic surgery have probable cognitive impairment preoperatively is not surprising given the same prevalence of cognitive impairment in other clinical studies ${ }^{[5-6,21-22]}$.In addition, this study is not limited to one type of thoracic surgery (including VATS/thoracotomy/robotic assisted VATS), so our study is applicable to a wider range of elderly patients undergoing elective thoracic surgery.

Preoperative cognitive impairment is a risk factor for postoperative adverse events and hospitalization [2325]. Recent evidence suggests that poor preoperative cognitive function increases the risk of recent postoperative complications and the cost of care. Culley et al. ${ }^{[16]}$ explored that preoperative cognitive scores in elderly patients undergoing elective orthopedic surgery (Mini-Cog score $\leq 2$ points) were associated with increased postoperative delirium, length of stay and increased likelihood of nonresidential placement after discharge, but not associated with other complications. Judith et al. ${ }^{[17]}$ evaluated preoperative cognition in elderly patients undergoing elective vascular surgery based on the MoCA scale. The results suggest that low preoperative cognitive scores are independently associated with preoperative vulnerability scores (EFS, Edmonton Frail Scale $\geq 6.5$ ), but not related to postoperative length of stay. And furthermore, Chen et al. ${ }^{[26]}$ used MMSE to evaluate the preoperative cognition of elderly patients who were scheduled to undergo open lobectomy. The results showed that low preoperative cognitive score was related to the risk of pulmonary complications and the length of stay, but not to the cost of hospitalization.

Based on the data from this study, $\mathrm{MCl}$ based on MoCA scale preoperatively were more likely to have a longer hospital length of stay $(\mathrm{OR}=2.355,95 \% \mathrm{Cl}=1.137$ to $4.877, P=0.021)$. However, it does not increase the risk of postoperative pulmonary complications and other complications. Therefore, we infer that preoperative $\mathrm{MCl}$ does not lead to prolong postoperative hospital stay by increasing postoperative complications, and the possible mechanism is to aggravate PND ${ }^{[5,10-13]}$. Moreover, the sample size of this study based on the hospital length of stay may be one of the reasons for the difference in postoperative complications between the two groups. Finally, we also analyze the relationship between preoperative $\mathrm{MCl}$ and the hospital length of stay in patients with PPCs, mainly considering that PPCs is a common complication after thoracic surgery, and directly lead to prolong hospital stay. The results of this study indicate that preoperative $\mathrm{MCl}$ could also predict the hospital length of stay in patients with PPCs (OR $=6.867,95 \% \mathrm{Cl}=1.116$ to $42.257, P=0.038$ ).

This study also has certain limitations. Although there is no exact "gold standard" for assessing mild cognitive impairment, only a single MoCA scale for preoperative mild cognitive function screening may occur positive. Additionally, this study do not evaluate the postoperative cognitive status of elderly patients, and could not determine the postoperative cognitive changes in elderly patients with $\mathrm{MCl}$ before surgery. Of course, the main purpose of this study was to observe the relationship between preoperative cognitive function and non-cognitive adverse clinical outcomes. 


\section{Conclusions}

This study demonstrates that the prevalence of undiagnosed probably $\mathrm{MCl}$ among elderly patients scheduled for thoracic surgery is high (49\%) and are not easily recognized by clinicians. Such impairment is associated with a longer hospital stay and LOS-PPCs, while it is not possible to conclude that it is related to the incidence of pulmonary complications and other complications after surgery. Therefore, we should pay more attention to the preoperative cognition of elderly patients, and provide more care for those at high risk to promote rehabilitation during perioperative.

\section{Abbreviations}

ASA: American Society of Anesthesiologists; BIS: Bispectral index;

BMI: body mass index; $\mathrm{MCl}$ : mild cognitive impairment;

PPCs: postoperative pulmonary complications; PACU: Post anaesthetic care unit;

GA-PA: General anesthesia combined paravertebral;

VATS: video-assisted thoracoscopic surgery.

\section{Declarations}

\section{Acknowledgements}

The authors would like to thank the nurse anesthetists in the operating room of the Shanghai Chest Hospital, Shanghai, Republic of China, for their involvement and support.

\section{Disclosure/Funding}

This work was supported by Shanghai Municipal Science and Technology Committee (Western Medicine Guided Project) 16411967600 Fund and Shanghai Municipal Commission of Health and Family Planning Project (201840319).

\section{Availability of data and materials}

The authors are reluctant to share data related to this study, and patients who participated in the study also did not want the data to be published.

\section{Authors Contributions}


CYT performed the data analysis, manuscript writing and editing. DHW conducted the data acquisition and performed the clinical studies. YFS prepared the manuscript and acquired the data. MYX designed the study and the concepts. All authors have read and approved the final version of the manuscript.

\section{Competing Interests}

No conflicts of interest are declared.

\section{Ethics approval and consent to participate}

This study was approved by the Institutional Review Board (KS1862) of Shanghai Jiao tong University Shanghai Chest Hospital with the consent of the patient or family member and signed informed consent (Chinese Clinical Trial Registry number, ChiCTR1800019526).

\section{References}

1.Ficarra B J. Preoperative biochemical evaluation of the surgical patient[J]. The American Journal of Surgery, 1949, 78(4): 504-506.

2.Fischer S P, Bader A M, Sweitzer B. Preoperative evaluation[J]. Miller's anesthesia, 2010, 7: 1019-22.

3.O'Hanlon S,Rechner J . Optimising pre-operative assessment for older people[J]. Anesthesia, 2018.

4.Crosby G, Culley D J, Hyman B T. Preoperative Cognitive Assessment of the Elderly Surgical Patient: A Call For Action[J]. Anesthesiology, 2011, 114(6):1265-8.

5.Plassman BL, Langa KM, Fisher GG et al: Prevalence of cognitive impairment without dementia in the United States[J]. Ann Intern Med 2008; 148:427-34.

6.Culley D J, Flaherty D, Reddy S, et al. Preoperative Cognitive Stratification of Older Elective Surgical Patients[J]. Survey of Anesthesiology, 2016, 60(6):241-243.

7.Silbert BS, Evered LA, Scott DA. Incidence of postoperative cognitive dysfunction after general or spinal anesthesia for extracorporeal shock wave lithotripsy. Br J Anaesth. 2014; 113:784-791.

8.Selnes OA, Grega MA, Bailey MM, Pham LD, Zeger SL, Baumgartner WA, McKhann GM. Cognition 6 years after surgical or medical therapy for coronary artery disease. Ann Neurol.2008; 63:581-590.

9. Price CC, Garvan CW, Monk TG. Type and severity of cognitive decline in older adults after noncardiac surgery. Anesthesiology. 2008; 108:8-17. 
10.Racine A M, Fong T G, Gou Y, et al. Clinical outcomes in older surgical patients with mild cognitive impairment[J]. Alzheimer\"s \& Dementia, 2017: S1552526017338141.

11.Bekker A, Lee C, Santi S D, et al. Does mild cognitive impairment increase the risk of developing postoperative cognitive dysfunction? [J]. The American Journal of Surgery, 2010, 199(6):0-788.

12.Moller J T, Cluitmans $P$, Rasmussen $L$ S, et al. Long-term postoperative cognitive dysfunction in the elderly ISPOCD1 study. ISPOCD investigators. International Study of Post-Operative Cognitive Dysfunction. [J]. Lancet, 1998, 351(9106):857-861.

13.Steinmetz J, Christensen K B, Lund T, et al. Long-term consequences of postoperative cognitive dysfunction[J]. Anesthesiology, 2009, 110(3):548.

14.Chow WB, Rosenthal RA, Merkow RP, Ko CY, Esnaola NF American College of Surgeons National Surgical Quality Improvement P, American Geriatrics S. Optimal preoperative assessment of the geriatric surgical patient: a best practices guideline from the American College of Surgeons National Surgical Quality Improvement Program and the American Geriatrics Society. J Am Coll Surg. 2012; 215:453-466.

15.Tan J, Li N, Gao J, et al. Optimal cutoff scores for dementia and mild cognitive impairment of the Montreal Cognitive Assessment among elderly and oldest-old Chinese population. [J]. 2015.

16.Culley D J, Flaherty D, Fahey M C, et al. Poor Performance on a Preoperative Cognitive Screening Test Predicts Postoperative Complications in Older Orthopedic Surgical Patients[J]. Anesthesiology, 2017:1.

17.Sun $\mathrm{Y}$, Gao W, Zheng H, et al. Pulmonary lobectomies for patients with cognitive impairment: the importance of postoperative respiratory care[J]. Annals of Translational Medicine, 2015, 3(14):195.

18.Chen K L, Xu Y, Chu A Q, et al. Validation of the Chinese Version of Montreal Cognitive Assessment Basic for Screening Mild Cognitive Impairment[J]. Journal of the American Geriatrics Society, 2016.

19.Nasreddine ZS, Jing Gao (2012) Montreal Cognitive Assessment: A screening tool for detecting mild cognitive impairment and early dementia [Chinese]. Chin J Neurol 45,135-137.

20.Nasreddine ZS, Phillips NA, Bedirian V, et al. The Montreal Cognitive Assessment, MoCA: a brief screening tool for mild cognitive impairment. J Am Geriatr Soc. 2005; 53:695-699.

21.Roberge G, Stortz S K, Frankel W C, et al. Identifying Prevalence and Risk Factors for Mild Cognitive Impairment in Adults Presenting for Urological Evaluation[J]. Urology, 2016: S0090429516300607.

22.Na S, Yy Y. Use of the Montreal Cognitive Assessment test to investigate the prevalence of mild cognitive impairment in the elderly elective surgical population[J]. Anesthesia \& Intensive Care, 2016, 44(5):581. 
23.Schupf N, Tang MX, Albert SM, Costa R, Andrews H, Lee JH, Mayeux R. Decline in cognitive and functional skills increases mortality risk in nondemented elderly. Neurology. 2005; 65:1218-1226.

24.Phelan EA, Borson S, Grothaus L, Balch S, Larson EB. Association of incident dementia with hospitalizations. JAMA. 2012; 307:165-172.

25.Toot S, Devine M, Akporobaro A, Orrell M. Causes of hospital admission for people with dementia: a systematic review and meta-analysis. J Am Med Dir Assoc. 2013; 14:463-470.

26.Jsl P. The prevalence and impact of undiagnosed cognitive impairment in older vascular surgical patients[J]. Journal of Vascular Surgery, 2014, 60(4):1002-1011.e3.

\section{Tables}

Table 1 Pre- and intraoperative patient characteristics 


\begin{tabular}{|c|c|c|}
\hline Baseline characters & group N $(\mathrm{n}=78)$ & group AN $(\mathrm{n}=76)$ \\
\hline Gender(male\%) & $46 \%$ & $49 \%$ \\
\hline Age (years) & $68.6 \pm 3.7$ & $69.8 \pm 4.5$ \\
\hline BMI $\left(\mathrm{kg} / \mathrm{m}^{2}\right)$ & $23.17 \pm 3.07$ & $23.14 \pm 4.19$ \\
\hline Education level & $10 / 27 / 23 / 18$ & $32 / 31 / 9 / 4^{\mathrm{a}}$ \\
\hline Primary school & 10 & 32 \\
\hline Junior High School & 27 & 31 \\
\hline Senior High School & 23 & 9 \\
\hline $\begin{array}{l}\text { University } \\
\text { ASA II/III } \\
\text { Hypertension (\%) } \\
\text { Diabetes (\%) } \\
\text { Cerebral infarction (\%) } \\
\text { Radiotherapy and Chemotherapy (\%) } \\
\text { Operative time } \text { min } \square \\
\text { Surgical procedure }\end{array}$ & $\begin{array}{l}18 \\
66 / 12 \\
44 \% \\
17 \% \\
6 \% \\
6 \% \\
90.2 \pm 48.3 \\
64 / 7 / 7\end{array}$ & $\begin{array}{c}4 \\
60 / 16 \\
47 \% \\
13 \% \\
8 \% \\
4 \% \\
92.0 \pm 39.1 \\
65 / 7 / 4\end{array}$ \\
\hline VATS & 64 & 65 \\
\hline Thoracotomy & 7 & 7 \\
\hline $\begin{array}{l}\text { Robotic assisted VATS } \\
\text { Type of operation }\end{array}$ & $\begin{array}{l}7 \\
24 / 54\end{array}$ & $\begin{array}{c}4 \\
21 / 55\end{array}$ \\
\hline anatomical lobectomy & 54 & 55 \\
\hline $\begin{array}{l}\text { non-anatomical lobectomy } \\
\text { Type of anesthesia }\end{array}$ & $\begin{array}{l}24 \\
62 / 16\end{array}$ & $\begin{array}{l}21 \\
58 / 18\end{array}$ \\
\hline GA & 62 & 58 \\
\hline $\begin{array}{l}\text { GA-PA } \\
\text { Total fluid volume (ml) } \\
\text { Intraoperative hypoxemia } \\
\text { Duration from PACU to extubation (min) }\end{array}$ & $\begin{array}{c}16 \\
1066 \pm 270 \\
4 \% \\
31.5 \pm 12.9\end{array}$ & $\begin{array}{c}18 \\
1046 \pm 216 \\
3 \% \\
31.9 \pm 17.5\end{array}$ \\
\hline
\end{tabular}

Values are $\mathrm{n}(\%)$, mean \pm SD or the number of patients. BMI: body mass index; ASA: American Society of Anesthesiologists; VATS: video-assisted thoracoscopic surgery; GA-PA: General anesthesia combined paravertebral ; PACU: Post anaesthetic care unit. $P^{a}<0.05$.

Table 2 Univariate and multivariate analysis of preoperative MCI screening results predict the risk of length of stay 


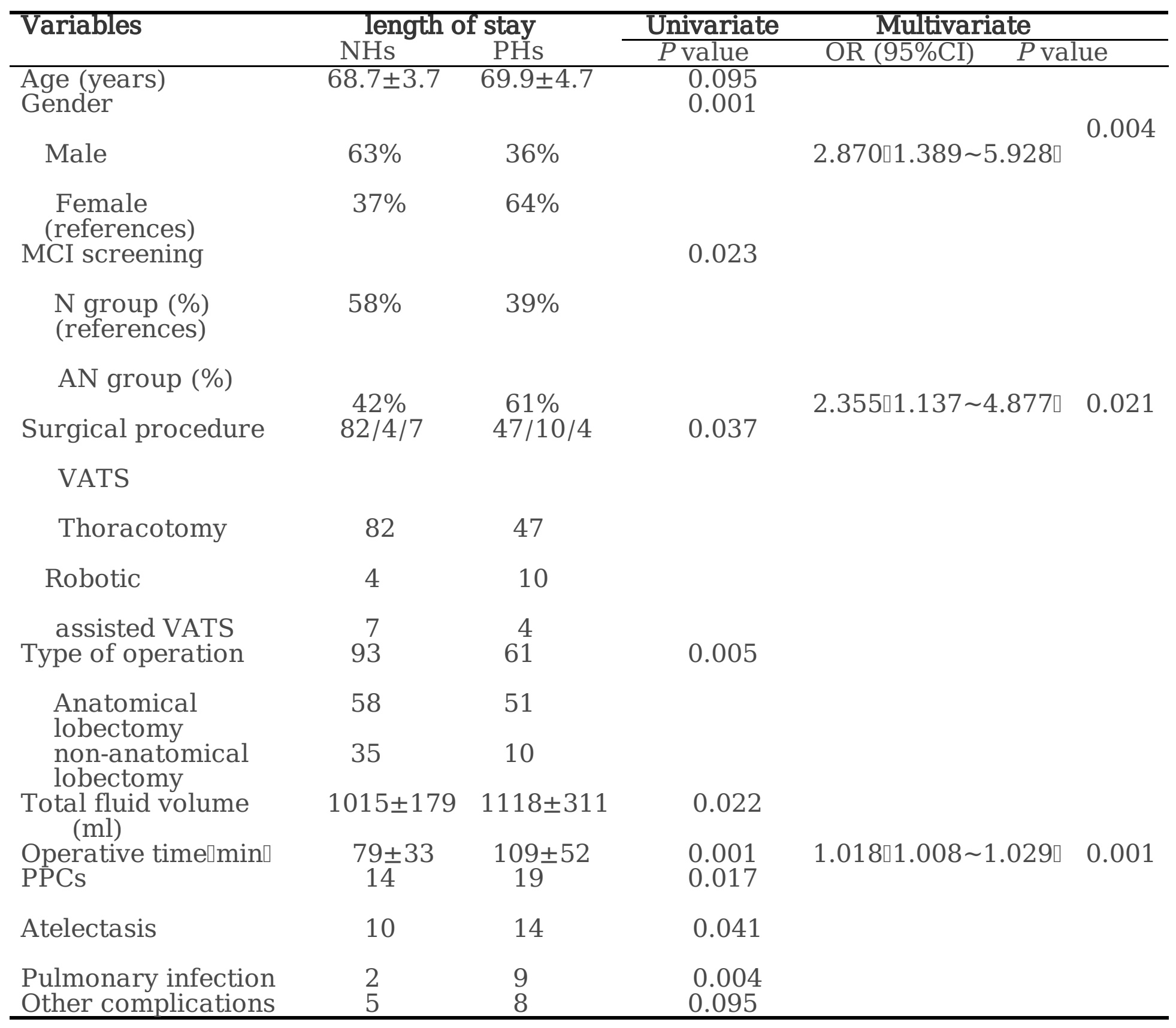

Values are $\mathrm{n}(\%)$, mean \pm SD or the number of patients. $\mathrm{CI}=$ confidence interval; $\mathrm{OR}=$ odds ratio;

MCI: mild cognitive impairment; VATS: video-assisted thoracoscopic surgery; PPCs: Postoperative pulmonary complications NHs: Normal hospital stay; PHs: Prolonged hospital stay. 
Table 3 Univariate and multivariate analysis preoperative MCI screening to predict the length of stay in patients with PPCs

\begin{tabular}{|c|c|c|c|c|c|c|}
\hline \multirow[t]{2}{*}{ Variables } & \multicolumn{2}{|c|}{ length of stay } & Univariate & \multicolumn{2}{|c|}{$\begin{array}{c}\text { Multivariate } \\
\end{array}$} & \\
\hline & NHs & PHs & $P$ value & OR $(95 \% \mathrm{CI})$ & $P$ valt & \\
\hline & & & & & & \\
\hline Male & 9 & 10 & & & & \\
\hline $\begin{array}{l}\text { Female (references) } \\
\text { MCI screening }\end{array}$ & $\begin{array}{l}12 \\
21\end{array}$ & $\begin{array}{c}4 \\
14\end{array}$ & 0.053 & & & \\
\hline $\begin{array}{l}\mathrm{N} \text { group (\%) } \\
\text { (references) }\end{array}$ & 13 & 4 & & & & \\
\hline AN group (\%) & & & & & & \\
\hline Type of operation & $9^{8}$ & $\begin{array}{l}10 \\
26\end{array}$ & 0.056 & $6.867 \square 1.116 \sim$ & $2.257 \square$ & 0.038 \\
\hline Anatomical & 1 & 13 & & & & \\
\hline non-anatomical & 8 & 13 & & & & \\
\hline $\begin{array}{l}\text { Iobectomy } \\
\text { Total fluid volume (ml) } \\
\text { Operative time } \llbracket \min \rrbracket\end{array}$ & $\begin{array}{c}1004 \pm 196 \\
87 \pm 46\end{array}$ & $\begin{array}{c}1228 \pm 448 \\
139 \pm 69\end{array}$ & $\begin{array}{l}0.097 \\
0.012\end{array}$ & $1.024 \square 1.003 \sim$ & $.045 \square$ & 0.026 \\
\hline
\end{tabular}

Values are $\mathrm{n}(\%)$, mean \pm SD or the number of patients. $\mathrm{CI}=$ confidence interval; OR $=$ odds ratio;

MCI: mild cognitive impairment; PPCs: postoperative pulmonary complications; NHs: Normal hospital stay; PHs: Prolonged hospital stay.

\section{Figures}




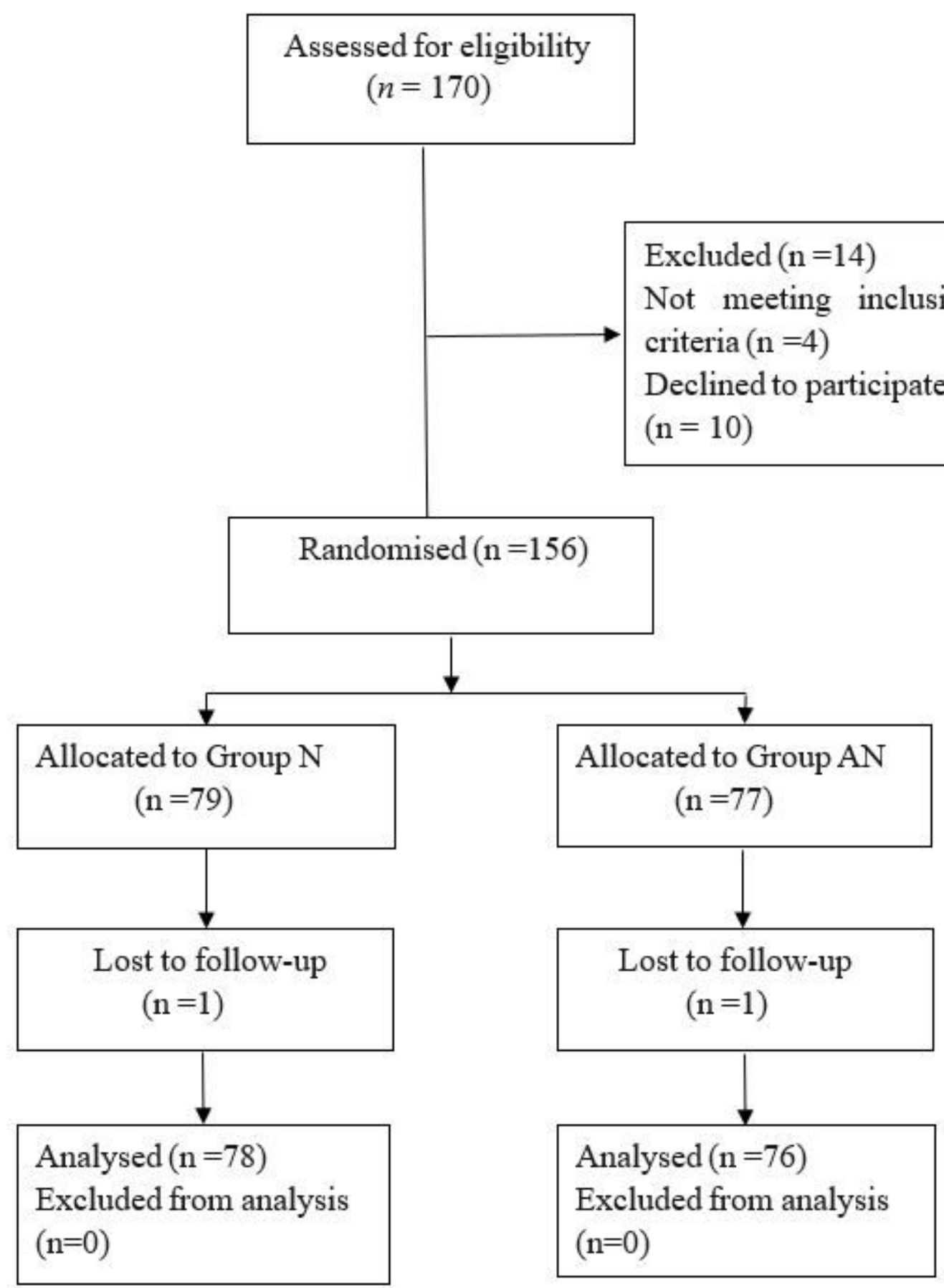

Figure 1

CONSORT flow diagram 


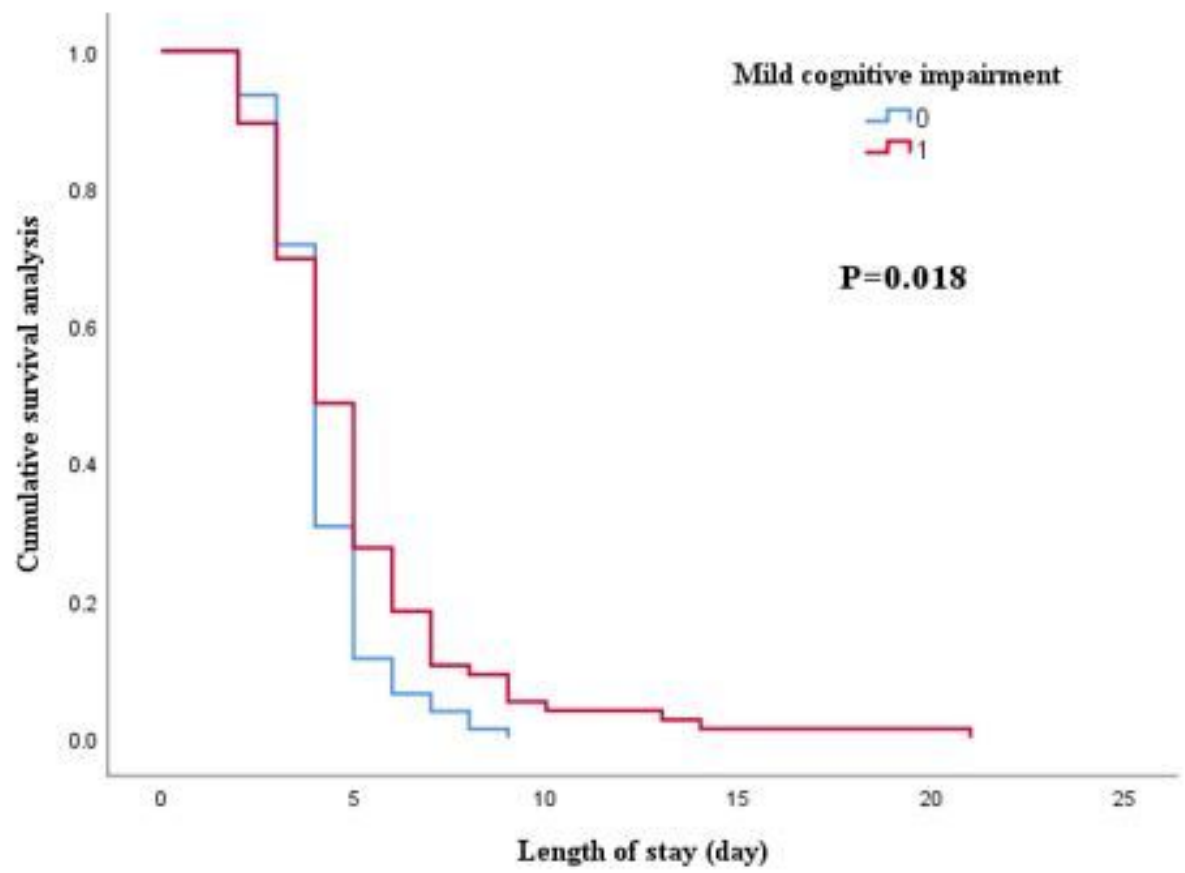

Figure 2

Preoperative mild cognitive impairment predicts the length of stay

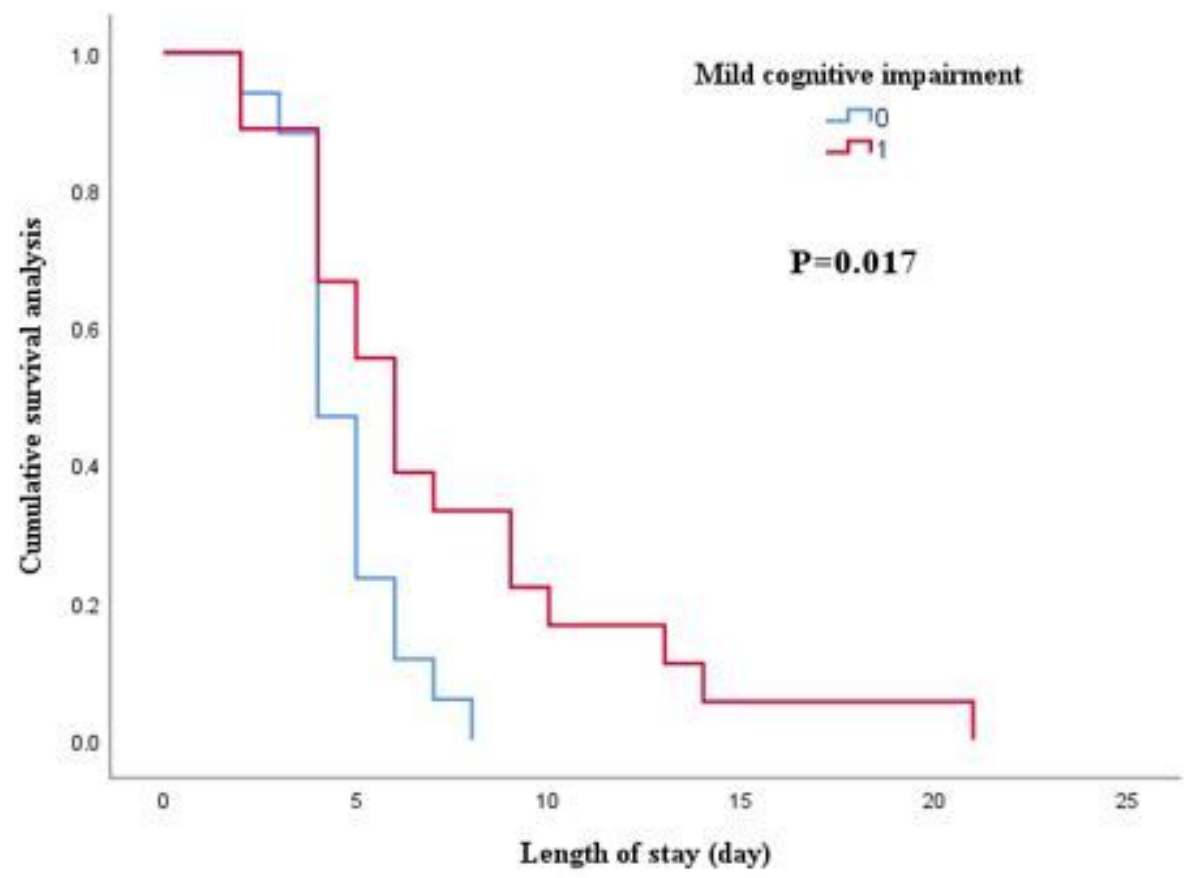

Figure 3

Preoperative mild cognitive impairment predicts the length of stay in patients with PPCs 